\title{
A physico-chemical perspective of plant polysaccharides in relation to glucose absorption, insulin secretion and the entero-insular axis
}

\author{
BY PETER R. ELLIS, PHILLIPPA RAYMENT AND QI WANG \\ Biopolymers Group, Division of Life Sciences, King's College London, \\ Campden Hill Road, Kensington Campus, London W8 $7 A H$
}

There is a growing realization that studies of the physico-chemical structure and properties of foods in the gut lumen will greatly assist our understanding of the function of the gastrointestinal (GI) tract in relation to human health and disease (British Nutrition Foundation, 1990). However, it is difficult to make reliable predictions of the behaviour of foods in the gut, because there are serious deficiencies in our knowledge and methodology in this area. Our knowledge of GI function at the luminal, mucosal and cellular levels is unlikely to make significant progress until we have a detailed and basic understanding of the structure and properties of foods. Thus, for example, the behaviour of a food matrix in the GI environment is of critical importance to our understanding of the kinetics of nutrient bioavailability. Interestingly, the mechanical properties of foods have been studied extensively in relation to their behaviour in the mouth, in order to understand, for example, the process of mastication and how human subjects perceive texture (Blanshard \& Mitchell, 1988; Vincent, 1990). This approach has not been used in any fundamental way, however, to study the relationship between the physical properties of foods and their effects on GI function and systemic responses, such as meal-stimulated blood metabolite and hormone levels.

Non-starch polysaccharides (NSP) from plant food sources are of special interest to nutritionists in that they have marked effects on the physical properties of digesta at all sites of the GI tract (Selvendran et al. 1987; Eastwood \& Morris, 1992; Morris, 1992). Thus, the consumption of NSP ('dietary fibre') in the form of plant cell walls or purified extracts can strongly influence GI function, including the rate and extent of nutrient absorption in the small intestine and bacterial fermentation in the colon. The present paper is a brief review of the possible physico-chemical mechanisms by which NSP, mainly the water-soluble polymers, influence glucose absorption, insulin secretion and the entero-insular axis.

\section{EARLY VIEWS ABOUT THE DIGESTION OF STARCHY FOODS}

Starch from a broad range of plant foods, including cereals, legumes and tubers (especially the potato), provides the main source of glucose in the human diet (British Nutrition Foundation, 1990). Our views about the digestibility of starchy foods have changed dramatically since the late 1970 s (Dreher et al. 1984). Previous work has shown that pancreatic amylase (EC 3.2.1.1) is present in excess in the intestinal lumen and that starch is rapidly hydrolysed after ingestion of a 'liquid' starch-rich test meal (Dahlqvist \& Borgström, 1961; Fogel \& Gray, 1973). It was concluded, therefore, that intraluminal digestion is not the rate-limiting step. Thus, the traditional view of the digestion of starchy foods has been that all starches are digested rapidly at more or less the same rate and to the same extent. More recently, however, the results of numerous in vitro digestibility studies and metabolic studies in experimental animals and human subjects have demonstrated that 
starchy foods are digested at markedly different rates (British Nutrition Foundation, 1990; Grenfeldt et al. 1991). Moreover, a significant proportion of starch can escape digestion in the small intestine and reach the colon where it is fermented by bacterial enzymes, the main products of which are volatile fatty acids (Stephen et al. 1983; British Nutrition Foundation, 1990; Silvester et al. 1995). All these observations explain why many acute studies have shown large differences in the the postprandial rise in blood glucose and insulin concentrations in response to different foods containing isoglucidic amounts of available carbohydrate (Crapo et al. 1977; Jenkins et al. 1986).

The results of these early studies led to the introduction of the term glycaemic index, which is used for ranking foods according to the incremental blood glucose response they produce (Jenkins et al. 1986; British Nutrition Foundation, 1990). Thus, many processed cereal products such as wheat bread and cornflakes have significantly higher glycaemic indices than leguminous foods such as kidney beans (Phaseolus vulgaris L.). The nutritional significance of the glycaemic index has not been fully evaluated, but its use in the dietary management of diabetes shows considerable promise (Jenkins et al. 1986). Many food-related factors are known to influence the blood glucose and insulin profiles, including the structural and mechanical properties of a food, the characteristics of starch in foods and the presence of other food components such as 'dietary fibre' or NSP (British Nutrition Foundation, 1990).

\section{PROPERTIES AND BIOLOGICAL EFFECTS OF NSP}

Since the late 1950s, numerous reports have shown that dietary supplements of NSP can significantly modulate carbohydrate and lipid metabolism in experimental animals and human subjects (Lin et al. 1957; Fisher et al. 1966; Jenkins et al. 1976; Gee et al. 1983). For example, the addition of water-soluble types of NSP (s-NSP), such as pectin and guar gum, to glucose drinks or starchy meals is known to reduce postprandial hyperglycaemia and plasma insulin concentrations in healthy and diabetic human subjects (Jenkins et al. 1976, 1977; Morgan et al. 1985; Ellis et al. 1991; Braaten et al. 1992; Gatenby et al. 1996). An early study by Jenkins et al. (1978) indicated that the glucose-lowering effect of s-NSP seemed to be dependent on their property of generating high viscosity in aqueous solutions. The current research interests of a number of groups, including our own, has focused, therefore, on the relationship between the rheological properties of polysaccharide gums and glucose absorption.

\section{Physico-chemical structure and properties of NSP}

Most of the NSP present in a typical British diet is in the form of plant cell walls, which comprise an extremely complex, heterogeneous network of cellulose, hemicelluloses and pectic substances, the amounts and relative proportions of which vary depending on factors such as the type and maturity of the plant tissue (Selvendran et al. 1987; Carpita, 1990). The hemicelluloses in particular consist of a broad range of polymeric components; thus, xyloglucans are commonly found in the plant cell walls of fruits and vegetables, whereas arabinoxylans and mixed linkage $(1 \rightarrow 3)(1 \rightarrow 4)-\beta$-D-glucan (or simply $\beta$-glucan) predominate in wheat- and oat-based food products respectively. The non-carbohydrate components (lignin, protein, cutin etc.) are, quantitatively, minor components of plant cell 
walls. Nevertheless, lignin and other non-carbohydrate components are known to form covalent cross-links with polysaccharides of cell walls (Selvendran et al. 1987; Carpita, 1990) and are likely, therefore, to modify significantly the properties and biological activity of dietary fibre (Selvendran et al. 1987).

The distinction made between water-soluble and -insoluble NSP is based on in vitro studies and chemical analyses of cell-wall material. It is not known, therefore, to what degree the soluble fractions of plant cell walls (e.g. pectins from vegetable sources) solubilize in the stomach and small intestine, although this is more likely to occur if the food has been mechanically and/or heat processed (Selvendran et al. 1987; Thibault et al. 1992). Assuming that some degree of solubilization takes place in the GI tract, the magnitude of effect of the soluble fraction on the rheological properties of digesta will be critically dependent on the molecular size and concentration of the polymer in the aqueous phase (see pp. 884-885).

Quantitative estimates of dietary fibre in foods, including detailed analysis of the types and proportion of monosaccharide residues, are unlikely per se to provide information about the physical properties and, therefore, the physiological function of NSP. Although information on the behaviour of dietary fibre in the GI tract is lacking, there is a plethora of literature on the physical properties of purified polysaccharides used in the food industry as functional polymers (e.g. to improve food texture).

Fundamental to our understanding of the physical properties of polysaccharides, like all biopolymers, is their molecular shape or conformation (Rees, 1977). The shape of polysaccharides in three dimensions can be stable or in a continuous state of fluctuation, depending on the particular polysaccharide and the prevailing environmental conditions. Whichever conformation predominates, this will determine how atoms and groups in the polymer are orientated to the outside and, hence, interact with other molecules, solvents and biological surfaces. Molecular shape will determine, for example, the relative solubility of polysaccharides in an aqueous medium, a property that is of paramount importance in biological systems including, of course, the process of digestion and absorption of nutrients in the mammalian gut.

Polysaccharides from industrial sources or naturally present in plant foods exhibit a wide spectrum of physical properties (Fig. 1), reflecting the nature and extent of intermolecular associations, which in turn are largely dependent on the shape of individual polymer chains (Morris, 1992). At one extreme end of this spectrum the polymer chains are packed tightly together into ordered assemblies such as cellulose microfibrils (Fig. 1), which are mechanically strong and almost totally resistant to hydration and swelling. At the other end of the spectrum polysaccharide chains can exist in solution as fluctuating, disordered coils, interacting with each other only by a process of physical entanglement (e.g. solutions of guar gum and oat $\beta$-glucan; Fig. 1). Between these extremes are hydrated, swollen networks characteristic of polysaccharide gels, plant tissues and many processed foods, within which co-exist regions that are ordered ('junction zones') and disordered (solubilizing sequences).

The majority of polysaccharides, including the purified s-NSP used in nutritional studies, exist in solution as fluctuating 'random coils'. The properties of these conformationally-disordered polymers in solution (e.g. viscosity) are dependent largely on the number and molecular size of the polymer chains, which in turn are likely to be critical determinants of their physiological activity. In solution, molecular size can be estimated by 
Ordered assemblies

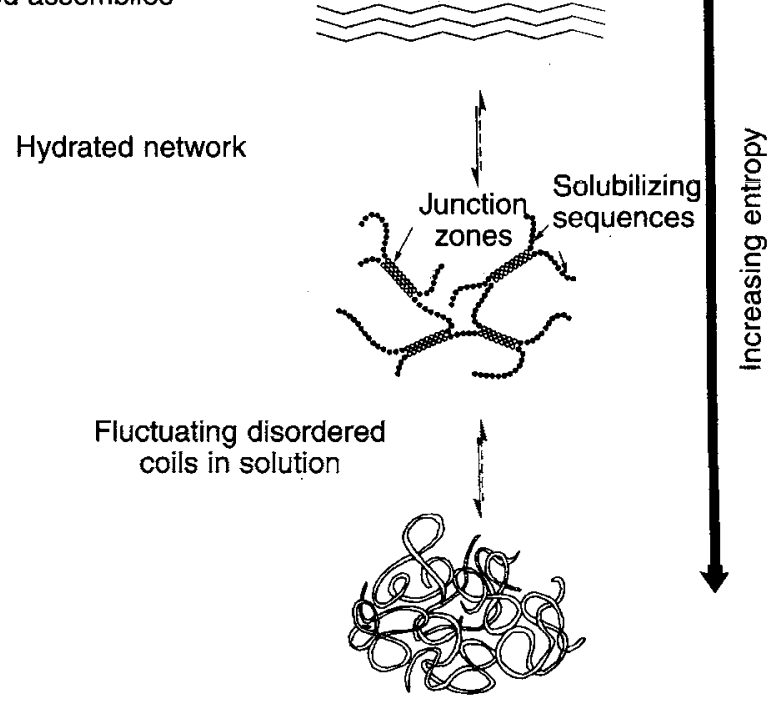

Fig. 1. Schematic representation of the spectrum of physical properties of NSP.

the volume occupied by individual polymer coils (i.e. degree of space occupancy). The most direct index of the 'hydrodynamic volume' of disordered coils is intrinsic viscosity

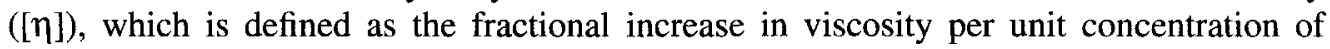
polymer under conditions of extreme dilution (Robinson et al. 1982).

The high levels of viscosity associated with water-soluble polysaccharides are generated predominantly by interpenetration of individual polymer chains to form an entangled network. But this process will occur only at or above a critical polymer concentration, the so-called $\mathrm{C}^{*}$, the point at which polymer entanglement commences (Fig. 2). Thus, significantly above $\mathrm{C}^{*}$ individual chains can move about only by wriggling or 'reptating' through the entangled network of contiguous chains (de Gennes, 1979). The extent of this entanglement and, hence, viscosity is determined by the dimensionless product of concentration ( $c$; proportional to the number of chains present) and [ $\eta]$ (proportional to the volume that each chain occupies). The $\mathrm{c}$ value at which entanglement begins will obviously depend on the coil volume of a particular polymer. For solutions of guar gum, entanglement occurs when $\mathrm{c}[\eta]$ exceeds approximately $2 \cdot 5$, and thereafter viscosity increases at approximately $(\mathrm{c}[\eta])^{5}$, so that doubling either the concentration or $[\eta]$ increases viscosity by a factor of about 30 . The solution viscosity of guar gum and other random coils at $\mathrm{C}^{*}$ is usually only about ten times the viscosity of water (approximately $10 \mathrm{mPa} . \mathrm{s}$ ). Below $\mathrm{C}^{*}$, therefore, where individual polymer coils are able to move in the solvent with minimal interference from neighbouring chains, entanglement or viscosity will be negligible.

The viscosity or flow properties of random coil solutions can be characterized by using various rheological techniques. Rheology (from the Greek rheos meaning 'stream') is the branch of physical science concerned with the study of the flow and deformation of matter under the influence of externally-imposed mechanical forces (Dickinson, 1992; RossMurphy, 1994). Rheological systems can be characterized, therefore, by studying the relationship between two physical variables, stress, which is the force per unit area acting upon and within a material, and strain, which is the amount of deformation induced by the 


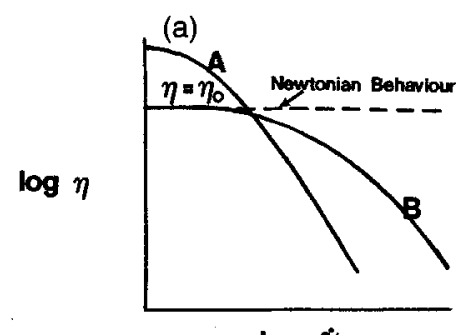

$\log \dot{\gamma}$

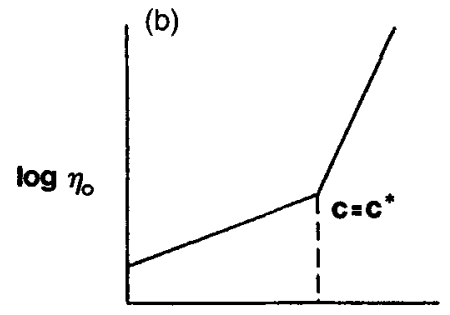

$\log \mathbf{C}$

Fig. 2. Schematic illustration of (a) shear rate $(\dot{\gamma})$ dependence of viscosity ( $\eta$ ) for solutions A and B and (b) the concentration (c) dependence of zero-shear viscosity $\left(\eta_{0}\right)$ for a typical 'random-coil' hydrocolloid. $\mathrm{C}^{*}$, critical polymer concentration (point at which polymer entanglement commences); for details, see p. 884 .

stress. For liquids such as solutions of polysaccharide gums, the stress depends not on the amount of deformation but on the rate of deformation. Shear viscosity $(\eta)$ is defined therefore as:

$$
\eta=\tau / \dot{\gamma}
$$

where $\dot{\gamma}$ is the rate of shear strain (or shear rate) and $\tau$ is shear stress. Liquids such as water or vegetable oil are classified as being Newtonian fluids because their viscosity does not change when measured under a wide range of rates of shear (i.e. shear stress is a strictly linear function of shear rate, see Fig. 2). For non-Newtonian fluids, shear stress is nonlinear in relation to increased rates of shear strain, meaning that viscosity is shear dependent. The more common type of non-Newtonian flow in food systems is shearthinning (or pseudoplastic) behaviour, where viscosity decreases with increasing shear rate. It is well known that solutions of random-coil polysaccharide exhibit shear-thinning behaviour, which can vary by at least a factor of 100 over the range of shear rates of practical importance (Fig. 2(a)). Viscosity is highest, therefore, at low shear rates, reaching a constant maximum at the so-called 'zero-shear' rate, and then a corresponding fall in viscosity with increasing shear rate. Obviously the degree of shear-thinning behaviour is critically dependent on the concentration and hydrodynamic volume of polymer chains (Fig. 2). Below $C^{*}$ (the onset of entanglement) individual coils are able to move about freely through the solvent with negligible entanglement of contiguous chains. Thus, before the onset of coil overlap, viscosity is only slightly dependent on the rate of shear strain (i.e. Newtonian behaviour), whereas above $\mathrm{C}^{*}$ viscosity becomes highly dependent on shear rate.

\section{Mechanisms underlying the physiological effects of NSP}

It is unlikely that there will be one unifying mechanism to explain precisely the physiological effects of NSP in the GI tract of man. A number of physico-chemical mechanisms may be involved, but which of these predominates will depend on various factors, such as the type of NSP, the form in which NSP are ingested and the background diet of the individual. Thus, for example, the mode of action of structurally-intact plant cell walls on nutrient absorption is almost certainly different from that of dietary supplements of s-NSP.

Most of the studies of the mechanism of action of s-NSP have involved the use of purified extracts of polysaccharides such as guar gum. More recent studies have also tested 
the biological activity of a $\beta$-glucan gum extracted from oat bran (Wood, 1993). Many of these extracts have structural features similar to polymer components found in plant cell walls and have served, therefore, as 'model' polysaccharides in nutritional studies. There is little doubt that studies of the physico-chemical properties of these 'model' polysaccharides will assist in the development of pharmaceutical preparations and fibre-rich foods for clinical use in the dietary treatment of disease (e.g. diabetes mellitus; Ellis \& Morris, 1991; Ellis et al. 1991). Moreover, these polysaccharide extracts may provide some understanding of the physiological activity of plant-cell-wall material, such as that found in cereal-bran products, some of which contain s-NSP with the capacity to generate high levels of viscosity in solution (Wood, 1993). 'Model' polysaccharides will be of much less use, however, when studying structurally-intact plant cell walls, which appear to act as a physical barrier to the digestion of intracellular nutrients (Würsch et al. 1986; Tovar et al. 1991).

The well-documented blood glucose-reducing effect of dietary supplements of s-NSP almost certainly depends on their capacity to increase viscosity of digesta in the stomach (Johansen et al. 1996) and the small intestine (Blackburn et al. 1984; Ellis et al. 1995). In very simple terms, high levels of viscosity will slow down many of the physiological processes associated with the digestion of foods and absorption of nutrients. For example, the results of many animal and human studies have shown that s-NSP can influence the rate of emptying of a meal from the stomach (Edwards \& Read, 1990). However, there are serious problems in accurately determining the time-course of gastric emptying, which is a complex physiological process. This is partly due to difficulties of evaluating differences in rates of emptying between solid and liquid phases of digesta (Rainbird \& Low, 1986; Meyer \& Doty, 1988) and also, previously, to the lack of reliable techniques for measuring stomach emptying.

Nevertheless, the view that s-NSP can reduce the rate of gastric emptying of a meal has been supported by evidence from studies of several species including rats (Leeds et al. 1979; Brown et al. 1988), dogs (Bueno et al. 1981; Meyer et al. 1988) and human subjects (Wilmhurst \& Crawley, 1980; Tadesse, 1982; Blackburn et al. 1984; Schwartz et al. 1988). Other studies in pigs (Rainbird, 1986; Rainbird \& Low, 1986), however, have shown that whilst the rate of emptying of the liquid phase of a meal is significantly reduced by the presence of guar gum, the emptying of the solid phase is unaffected. Moreover, no correlation was found between the rate of gastric emptying and postprandial hyperglycaemia in pigs (Rainbird \& Low, 1986) and human subjects (Blackburn et al. 1984) fed on diets containing guar gum. Contradictory results from studies of gastric emptying are probably due to differences in the types and mode of administration of NSP tested, and methods of measuring gastric emptying (Low, 1990).

Other important processes that take place in the stomach include the mechanical disruption of foods, degree of mixing of food with gastric secretions, and enzyme hydrolysis. In studies of the GI function of dogs, Meyer \& Doty (1988) have shown that guar gum impairs gastric trituration and sieving by increasing the viscosity of the stomach contents. Thus, when a guar-gum-containing meal of meat, bread, margarine and water was fed to dogs, there was a significant increase in the proportion of large food pieces reaching the small intestine (Meyer \& Doty, 1988). Not surprisingly, an increase in the proportion of large particles of food reaching the small intestine will reduce the rate of digestibility of nutrients, as a result of a corresponding decrease in surface area available for enzyme 
hydrolysis. Under circumstances where particulate components are suspended in an aqueous medium of high viscosity it is probably more difficult for the stomach to sieve out and disrupt the solid-like particles of food (i.e. 'hydrated networks'). Studies of the physical properties of digesta removed from the mid-jejunum of pigs, which were fed on semi-purified diets with and without guar gum, provide a useful illustration of the process that may be occurring in the stomach (Roberts et al. 1990a,b). In pigs fed on semi-purified diet, digesta samples were found to separate into solid and liquid phases within a period of about $30 \mathrm{~min}$. However, in the same pigs fed on the same diet but mixed into a fullyhydrated solution of guar gum the solid phase remained suspended in the digesta for up to $4 \mathrm{~h}$ after removal from the animal.

Since the presence of s-NSP in the gut severely inhibits digesta flow within the small intestine, this will almost certainly inhibit the physical mixing of nutrients and enzymes (e.g. pancreatic amylase), thereby reducing rates of digestion and movement of nutrients from the lumen to the mucosal epithelium. There is little doubt that a high level of digesta viscosity produced by hydrated guar gum in the GI tract severely inhibits the propulsive and mixing effects of intestinal contractions (Blackburn et al. 1984; Edwards et al. 1988). It seems from the limited data available that the gut responds to the 'anti-motility' actions of the viscous digesta by altering the pattern of intestinal contractions (Bueno et al. 1981; Cherbut et al. 1990) and also by increasing the volume of intestinal secretions (Roberts et al. 1990a,b). The effect of guar gum and similar polysaccharides on the mixing characteristics of digesta in the GI tract has not been thoroughly studied, but it is likely to be extremely complex. It has been suggested that an increase in viscosity of digesta will produce laminar or 'stream-line' flow, rather than turbulent or disorderly flow, which is characteristic of less-viscous fluids and facilitates efficient mixing of digesta in the GI tract (Macagno et al. 1982). Laminar-type mixing under viscous conditions would probably reduce the rate at which nutrients are presented to the epithelial surface and are then absorbed into the portal blood.

\section{EFFECT OF NSP ON THE RHEOLOGICAL BEHAVIOUR OF DIGESTA}

\section{Measurements of viscosity in the gastrointestinal tract: practical and theoretical considerations}

There have been few studies on the relationship between the rheological properties of s-NSP in vivo and meal-induced changes in blood metabolite and hormone levels either in experimental animals or human subjects. The main reason for the lack of data in this area is that there are practical difficulties in obtaining access to the GI tract, particularly in human subjects, and of taking reproducible and accurate viscosity measurements of intestinal contents. Moreover, there are many factors that complicate the interpretation of rheological behaviour in the GI tract (Ellis et al. 1986).

There is little doubt that the hydration kinetics of s-NSP is a critical factor. The importance of the rate and degree of hydration of s-NSP in determining their biological activity has been previously demonstrated (O'Connor et al. 1981; Heppell \& Rainbird, 1985; Ellis \& Morris, 1991). A simple in vitro method for monitoring the hydration kinetics of guar gum and similar polysaccharides has been used as a preliminary screening test for evaluating their potential clinical efficacy (Ellis \& Morris, 1991). The results indicated marked differences in rates of hydration and 'ultimate' viscosity levels between the various 
food-grade and pharmaceutical preparations of guar gum. These differences in viscosity were mainly due to substantial differences in particle size distribution and galactomannan content of the preparations. Interestingly, the two preparations that were least effective in generating solution viscosity have been shown to have little or no effect on glycaemic control in experimental animals (Heppell \& Rainbird, 1985) and human subjects (Holman et al. 1987; Baker, 1988).

The rheological behaviour of polymers in the GI tract is likely to be very complex and measurements of pure polymer solutions in the laboratory alone will not provide an accurate picture of polymer properties in vivo. There are, for example, a number of factors that seriously complicate the interpretation of viscosity measurements of animal and human digesta in mechanistic studies of NSP (Ellis et al. 1986). First, very little is known about the rates of movement in the gut, flow patterns in response to peristalsis are likely to change continually (Rainbird \& Sissons, 1985) and digesta will be subjected to very different shear rates in different regions of the gut and at different times. Second, the concentration of a particular polymer in the digesta during transit along the GI tract will vary considerably because of the marked flux in endogenous secretions and absorption of fluids, which vary both with time, site and composition of the diet (Zebrowska \& Low, 1987). Third, $\mathrm{pH}$ changes in the gut can also affect the charge of polyelectrolytes in solution, which, therefore, will alter solubility and viscous properties of the polymer. Fourth, some s-NSP may be prone to depolymerization in the upper part of the GI tract (stomach and small intestine), as seen in recent pig trials of oat $\beta$-glucan (Johansen $e t$ al. 1993, 1996). However, there is no evidence of this occurring at the same sites in the human gut. Finally, but not of least importance, is the contribution of undissolved food particles to the viscosity of digesta. The contribution made by the particulate components (a soft-filler phase) to the viscosity of digesta will also depend on the shape and size of the particles, which may vary widely in the small intestine. In the large intestine the volume occupied by particulate material in the digesta (faeces) will be considerably higher as a result of increased fluid absorption, so that at this site the contribution of the soft filler to viscosity is likely to be substantial. Indeed, digesta at this site may be regarded as a 'soft solid' rather than a 'hard liquid'. In studies of digesta, the effect of particulate components on the rheological behaviour of s-NSP is of crucial importance if we are to understand more precisely the mechanism of action of these polymers in the GI tract.

\section{In vitro models}

Digesta is an extremely complex heterogeneous system to investigate, and attempts to characterize it rheologically would be an ambitious task in the light of our present state of knowledge, using currently-available techniques. In view of this information, our laboratory has attempted to develop a mathematical model to describe the behaviour of a solution mixture of guar-gum galactomannan and variable amounts of rice-starch filler (Rayment et al. 1995). The rice starch, which was selected for size and homogeneity of the granules (particle size of compound granules, approximately $2-10 \mu \mathrm{m}$ ), was added to the guar-gum solutions, so that the galactomannan concentration in the aqueous medium was kept constant while the filler concentration was varied from 0 to $410 \mathrm{~g} / \mathrm{kg}$. Steady shear rheological measurements, which were performed at $25^{\circ}$ using a Rheometrics Fluids Spectrometer (RFS II; Rheometrics Inc., Piscataway, NJ, USA) with cone and plate and 


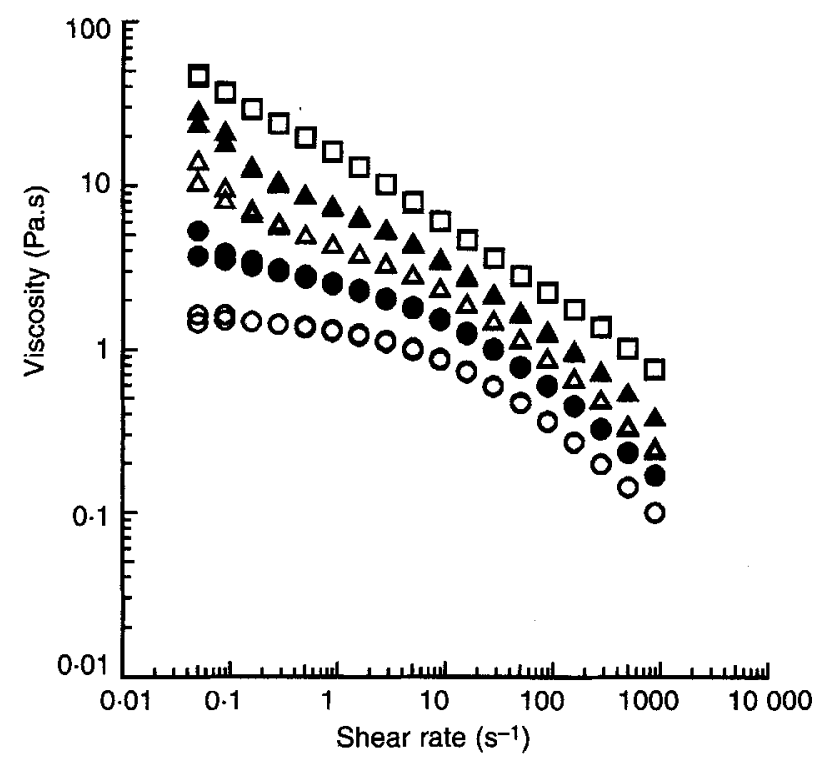

Fig. 3. Viscosity $v$. shear rate flow curve of aqueous solutions containing $10 \mathrm{~g}$ guar gum $/ \mathrm{kg}$ and increasing amounts of rice starch at concentrations of (g/kg dispersion): $0(O), 170(\bullet), 260(\Delta), 330(\Delta)$ and 410 ( $(\Delta)$. Duplicate data are presented to indicate reproducibility of results. Data taken from Rayment et al. (1995).

parallel-plate geometries, showed that rice starch as a 'filler' has marked effects on the rheological properties of a guar-gum galactomannan solution (Fig. 3). Steady shear measurements of the pure solution of galactomannan showed, as expected, a Newtonian plateau at low shear rates and increasing shear-rate dependence at high shear rates, the socalled power-law behaviour. However, on increasing the concentration of starch filler, not only is there a significant increase in viscosity, but the dispersion becomes more shear-rate dependent at lower shear rates and there is evidence of an apparent yield stress. This flow behaviour has been described with reasonable accuracy by using a yield stress modified Cross equation:

$$
\eta=\eta_{\infty}+\left(\eta_{0 \mathrm{x}}+\eta_{\infty}\right) /(1+(\mathrm{a} \dot{\gamma}) \mathrm{p})+\left(\tau_{\mathrm{x}} / \dot{\gamma}\right)
$$

where $\eta_{0 \mathrm{x}}$ and $\eta_{\infty}$ are limiting (Cross) viscosities, at zero and infinite shear rates, a and $\dot{\gamma}$ are relaxation time and shear rate respectively, and $\mathrm{p}$ is an exponent. Zero-shear viscosity and apparent yield stress data were determined from this equation and then fitted to mathematical models which include variables for volume fraction of the starch filler. Using these models a new master curve was then produced, which we believe will allow us to make predictions of the rheological behaviour of similar biopolymer dispersions where the relative proportion of the components is known. The Landel equation (Ross-Murphy, 1984) fitted particularly well with essentially 'spherical' granules of rice-starch filler and even with a heterogeneous wheat-starch food material (Rayment et al. 1995, 1996). Work is in progress to assess whether this equation fits data using rod-shaped particles such as microcrystalline cellulose. There is little doubt that data obtained from such in vitro models will be of importance in understanding the rheological behaviour of s-NSP in the GI tract. 


\section{Studies in experimental animals}

We have found the pig to be a useful animal model for studies of the rheological changes in the GI tract, particularly in experiments where we were also monitoring changes in glucose absorption and hormone secretion (see p. 892). In the initial rheological studies (Roberts et al. 1990a,b; Ellis et al. 1995) growing pigs were fitted with either a simple Tpiece cannula or re-entrant cannula, which were located in the mid-jejunum (about $2.0 \mathrm{~m}$ distal to the pylorus of the stomach), to allow removal of digesta samples for subsequent measurements of zero-shear viscosity. Although reliable measurements were obtained from using the simple T-piece cannula, the re-entrant type is considered to be a more useful preparation in that it allows the collection of all the gut contents from the conscious animal. Measurements of viscosity were taken within a few minutes of removing the digesta from pigs' jejunum usually at four to five shear rates. To make these measurements it was necessary to use a suitable rheological instrument that was also easily portable, robust and small enough to fit into the rather limited space of the pig house. For these reasons, a Brookfield DV-II rotoviscometer (Brookfield Instrumentation, Stoughton, MA, USA) fitted with a small sample adapter was selected, although one limitation of this instrument was the narrow shear-rate range over which viscosity measurements could be made. An additional problem is that if the size of some of the particles present in the digesta is greater than the gap between the sample chamber and the spindle, then this will seriously interfere with making reliable viscosity measurements. To minimize this, a small but variable fraction of solid material of particle size $>0.8-1.0 \mathrm{~mm}$ was removed by gentle sieving. It should be borne in mind, however, that such a procedure is likely to modify the rheological profile of the digesta and measurements of viscosity will almost certainly underestimate viscosity changes in vivo, as clearly illustrated in Fig. 3. Moreover, in some cases the removal of relatively large lumps of solid material containing significant quantities of sNSP and starch will have important mechanistic implications (see pp. 893-894).

To estimate zero-shear viscosity from the viscosity measurements we used a simplified form of the Cross equation which was developed by Morris (1990). Thus, the shearthinning behaviour of guar-gum galactomannan can be characterized by two variables, the maximum zero-shear viscosity $\left(\eta_{0}\right)$ and the shear rate $\left(\dot{\gamma}_{1 / 2}\right)$ at which viscosity is reduced to $\eta_{0} / 2$, using the following equation:

$$
\eta=\eta_{0} /\left(1+\left(\dot{\gamma} / \dot{\gamma}_{1 / 2}\right)^{0.76}\right)
$$

The values of $\eta_{0}$ and $\dot{\gamma}_{1 / 2}$ can be derived from the intercept and the slope of a simple linear plot of $\eta v . \eta \gamma^{0.76}$ respectively. Since an increase in concentration of particulate material in the digesta increases the power-law behaviour at low shear rates (Fig. 3), any extrapolation to maximum zero-shear viscosity from the experimental points should be regarded only as an approximation.

Nevertheless, the results of our early pig feeding trials showed that guar-gum galactomannan, which had been incorporated either into a liquid semi-purified (SP) diet or wheat bread, substantially increased the zero-shear viscosity of digesta in the mid-jejunum (Fig. 4). This effect was strongly dependent on the concentration of the guar-gum galactomannan in the diet, so that diets containing 20 and $40 \mathrm{~g}$ guar gum $/ \mathrm{kg}$ generated 14and 60-fold increases in average zero-shear viscosity (Fig. 4) respectively, relative to the control diet. However, it is interesting to note here that in many of these studies the differences in digesta viscosity in response to some guar-gum diets were surprisingly small 


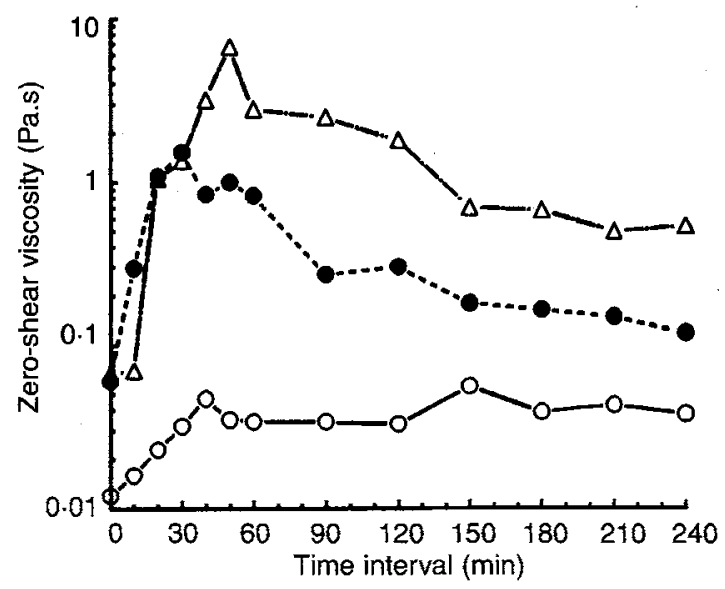

Fig. 4. 'Zero-shear' viscosity of jejunal digesta in pigs fed on control semi-purified (SP) diet (o); SP diet supplemented with $20(\bullet)$ and $40 \mathrm{~g}$ guar gum $/ \mathrm{kg}(\Delta)$. Viscosity measurements taken at fasting and twelve postprandial time intervals after the start of consumption of experimental diets. Values are means for four pigs. Data taken from Ellis et al. (1995).

when compared with in vitro viscosity measurements of the same diets. Thus, in pigs fed on wheat-bread meals containing guar gum, the viscosity profiles of digesta produced over $4 \mathrm{~h}$ were remarkably similar for high- and low-molecular-weight grades of polymer ingested at the highest dose (Roberts et al. 1990a). A plausible explanation for this is that a high dose of high-molecular weight galactomannan is diluted by a higher fluid content in the digesta, possibly as a result of increased endogenous secretions and/or decreased fluid absorption in the upper GI tract. This is not a surprising observation, since in earlier pig studies significant variations in the amount and content of pancreatic secretions in response to fibre-rich, cereal-based diets were reported by Zebrowska \& Low (1987). The results of experiments with guar gum in particular, therefore, suggest that one homeostatic mechanism by which the gut responds to an increased level of intraluminal viscosity is to alter the flux of fluid secretion and absorption.

A number of other research groups have shown significant increases in digesta viscosity in the stomach and small intestine of pigs fed on diets enriched with s-NSP (Cherbut et al. 1990; Johansen et al. 1996). It is very difficult, however, to compare these results with our own data since the experimental approach and the conditions used for determining viscosity in vivo vary considerably between the different research groups. In the study by Cherbut et al. (1990), for example, viscosity measurements were made on digesta samples removed from pigs that were killed $1 \mathrm{~h}$ after feeding guar gum. Johansen et al. (1996) showed that oat flour and rolled oats, containing slightly different amounts of $\beta$-glucan, produced relatively low levels of viscosity $(0.01-0.02 \mathrm{~Pa} . \mathrm{s})$ in the stomach of pigs during a $3 \mathrm{~h}$ postprandial period. In the same experiment, a $\beta$-glucan-rich oat-bran fraction produced a significantly higher viscosity $(0.2-0.4 \mathrm{~Pa} . \mathrm{s})$ during the same period. Measurements of viscosity were done, however, on the liquid phase of the digesta (i.e. supernatant fraction after centrifugation) at a shear rate of $45 \mathrm{~s}^{-1}$. This may partly explain why gastric viscosity was much lower than the jejunal viscosity levels seen in our study after the pigs were fed on guar gum (Fig. 4). Low rates of hydration and possible 
depolymerization of $\beta$-glucan in the oat fractions could also explain the low levels of gastric viscosity.

\section{EFFECT OF NSP ON NUTRIENT ABSORPTION AND HORMONE SECRETION}

Most studies of the effects of s-NSP on nutrient absorption in human subjects have normally involved taking measurements of glucose, insulin and gut hormone concentrations from the peripheral blood at discrete postprandial time intervals (Jenkins et al. 1976; Blackburn et al. 1984; Morgan et al. 1985; Ellis et al. 1991). However, measurements of glucose in the peripheral blood represent the net effect of absorption, production (in the liver) and metabolism of glucose. These measurements, therefore, do not provide a direct quantitative index of the rate and degree of glucose absorption. Moreover, few studies have attempted to quantify the effects of s-NSP on hormone secretion, although it is known that a reduction in postprandial hyperglycaemia is strongly linked to a diminished stimulation of the entero-insular axis, notably the insulinotrophic gut hormone, gastric inhibitory polypeptide (GIP; Morgan et al. 1985; Morgan, 1992).

In recent pig trials we have been able to obtain quantitative data on glucose absorption and the secretion of insulin, GIP and other hormones. This was done by measuring the differences in glucose and hormone concentrations between the hepatic portal vein and the peripheral blood (e.g. mesenteric artery), and, simultaneously, the flow-rate of the portal blood (Rérat et al. 1980, 1988). Thus, pigs were fitted with permanent indwelling catheters and an ultrasonic flow probe (Blake et al. 1993b; Ellis et al. 1995), to allow arterio-venous difference and blood flow measurements to be made. Using such techniques it has been possible to demonstrate for the first time that guar gum reduces glucose absorption, either when mixed into a semi-purified diet (Ellis et al. 1995) or incorporated into a wheat-bread product (Blake et al. 1993a,b). In all these studies, glucose absorption was substantially reduced (by as much as $42 \%$ in one study; Ellis et al. 1995), whilst apparent secretion of insulin and hormones of the entero-insular axis was also significantly decreased. The effects of guar gum on glucose absorption are consistent with data published by Simões Nunes \& Malmlöf (1992).

It is well known that the entero-insular axis, which possesses a neural as well as an endocrine component, makes a considerable contribution to total insulin secretion and is stimulated by the absorption of nutrients such as fat and carbohydrate (Morgan, 1992). Thus, the secretion of certain GI hormones and insulin is strongly dependent on the rate and site of active absorption of glucose into the portal blood. GIP in particular is generally considered to be a major endocrine component of the entero-insular axis and is known to have a powerful insulinotrophic effect in man. Other insulin-stimulating hormones, such as glucagon-like peptide-1 (the GLP-1 $1_{(7-36)}$ amide sequence) and cholecystokinin, have also been identified as important components of the entero-insular axis (Morgan, 1992). The effect of guar gum, either as part of a semi-purified diet or incorporated into bread, on the entero-insular axis has been recently demonstrated in pigs (Blake et al. 1993a; Ellis et al. 1995). In all these studies, total apparent insulin, GIP and GLP-1 production were significantly reduced. Furthermore, although no correlation was found between glucose absorption and insulin secretion, a significant correlation was seen between apparent GIP secretion and glucose absorption in the first hour (Ellis et al. 1995). This would suggest that the postprandial secretion of GIP is potentially a more reliable index of glucose absorption than insulin secretion. 


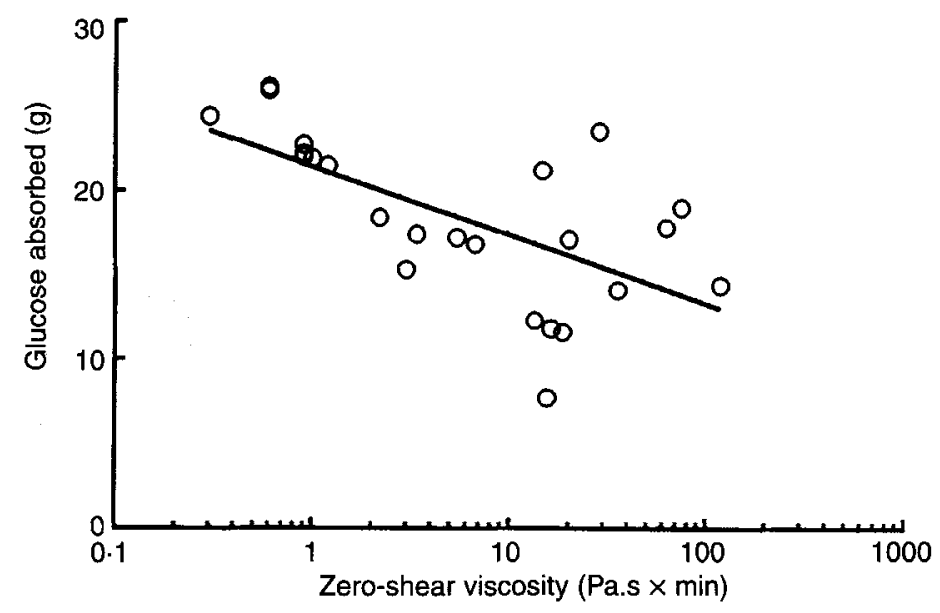

Fig. 5. Glucose absorbed over $4 \mathrm{~h} v$. zero-shear viscosity (Pa.s $\times$ min) at $30 \mathrm{~min}$ time intervals of jejunal digesta in pigs fed on diets with and without guar gum $(20$ or $40 \mathrm{~g} / \mathrm{kg})$. Values are means for four pigs. Correlation analysis of $\log$-linear model, $r^{2} 0.40, P<0.01$, df 22. Data taken from Ellis et al. (1995).

\section{RELATIONSHIP BETWEEN GLUCOSE ABSORPTION AND DIGESTA VISCOSITY}

Our initial studies in pigs fed on guar-containing foods indicated that maximum levels of viscosity of intraluminal contents of the small intestine (Roberts et al. 1990a,b) seemed to correspond with reductions in the post-meal blood glucose and insulin concentrations seen in pigs (Sambrook \& Rainbird, 1985) and human subjects (Jenkins et al. 1978; Morgan et al. 1985; Ellis et al. 1991). To investigate this further, the effects of guar-gum-containing diets on the viscosity of jejunal digesta were examined and correlated with changes in glucose absorption and hormone secretion. An inverse linear relationship was found between total glucose absorbed over $4 \mathrm{~h}$ (expressed as an integrated value) and the logarithm of zero-shear viscosity, suggesting that reductions in glucose are proportionately greater at low levels of viscosity in the mid-jejunum (Fig. 5). However, we need to be able to measure rheological changes at a number of sites of the GI tract simultaneously (e.g. stomach, duodenum and jejunum) to be able to evaluate the relationship between digesta viscosity and glucose absorption more fully.

Although there is no reliable information from human studies about the relationship between viscosity in vivo and glucose absorption, an inverse linear relationship between postprandial plasma glucose concentration and viscosity was reported in human subjects fed on glucose drinks containing oat $\beta$-glucan (Wood et al. 1994). The viscosity measurements were made on the original drinks, however, rather than on intestinal contents.

\section{INTERACTIONS BETWEEN STARCH AND NSP}

Although an increase in luminal viscosity is probably an important factor in explaining the blood glucose-lowering property of guar-gum galactomannan, other physical mechanisms may be involved, particularly when the polysaccharide is part of a food matrix such as wheat bread. We have suggested previously that in addition to its rheological effects guar 
gum may also inhibit the rate of digestion of the starch component of wheat bread by forming an 'enzyme-resistant barrier' around the starch granules (Ellis et al. 1991). To investigate this possibility, we examined the topological relationship between the galactomannan and starch in wheat bread, using a range of microscopical techniques, and also the effect of galactomannan on the rate of hydrolysis of wheat starch by pancreatic $\alpha$-amylase. Microstructural studies of digesta taken from pigs $4 \mathrm{~h}$ after they had been fed on guar-gum-containing wheat bread revealed that the galactomannan component of guar gum was still closely associated with individual starch granules in the bread (Brennen et al. 1996). This suggests that in addition to its rheological effects the galactomannan polymer may also act as a physical 'barrier' to enzyme-substrate interactions and the release of nutrients from the food matrix. Results of our in vitro digestibility studies are consistent with these observations, in that the hydrolysis of starch in guar-gum-wheat bread was reduced significantly compared with control bread (Brennan et al. 1996). This effect seemed independent of the molecular weight of the guar-gum galactomannan contained in the bread. This mechanism may partly explain why wheat bread containing guar-gum galactomannan of low molecular weight reduces postprandial hyperglycaemia and plasma insulin concentrations in diabetic (Gatenby et al. 1996) and non-diabetic (Ellis et al. 1991) human subjects.

\section{CONCLUSIONS}

Although the physico-chemical mechanisms underlying the physiological effects of s-NSP are incompletely understood, the modification of the rheological properties of digesta in the upper GI tract is of primary importance in reducing glucose absorption in man. Current evidence indicates that an increase in the viscosity of digesta can strongly impair gastric function, such as the processes of sieving and mixing, one consequence of which is an increase in the proportion of large-sized food particles entering the small intestine. The question of whether viscosity reduces the rate of gastric emptying of the solid phase of a meal has yet to be resolved, but the results of studies so far suggest that it is not a dominant factor. There is strong evidence to indicate that high viscosity in the gut lumen resists intestinal contractions, which normally facilitate the propulsion of digesta along the GI tract, thereby inhibiting the mixing of ingested food with intestinal secretions and decreasing the flow rate of solid components. Under these conditions, the rate at which glucose and other hydrolysed products of foods are presented to the mucosal surface ready for absorption will be severely inhibited. In fibre-enriched foods, s-NSP may also inhibit the digestion of starch by forming an enzyme-resistant barrier around the starch granules. The plasma insulin-sparing effect of s-NSP is thought to be partly attributed to a reduced stimulation of the entero-insular axis, notably GIP, rather than just a reduced rate of glucose absorption alone.

A detailed examination of the physico-chemical properties of s-NSP in the GI tract will significantly progress our understanding of the kinetics of digestion and absorption of carbohydrate and the role of the entero-insular axis. The concentration, molecular weight, degree of hydration and physical form (e.g. pharmaceutical preparations, plant cell walls) of s-NSP are all key factors influencing GI function.

The authors acknowledge the financial support of the BBSRC (Project Grant no. 29/F00662) and the Ministry of Agriculture, Fisheries and Food. The pig trials would not 
have been possible without the collaboration of many people, including Drs Fiona Roberts, Diane Blake, Graham Low, Ian Sambrook, Linda Morgan (Surrey University), and Knud Erik Bach Knudsen (NIAS, Denmark). The authors are particularly grateful to Dr Low (formerly of the AFRC Institute of Grassland and Animal Production, Shinfield), who helped to initiate much of the early and highly relevant work on NSP in pigs. We thank also Professor Ed Morris (Silsoe College) and our close colleague Professor Simon RossMurphy for helpful advice and numerous discussions on the rheological aspects of our work and the review. Thanks are also due to Ms Rachel Smith for her excellent artwork in preparation of the figures.

\section{REFERENCES}

Baker, P. (1988). Placebo-controlled trial of guar in poorly controlled type 2 diabetes. Practical Diabetes 5, $36-38$.

Blackburn, N. A., Redfern, J. S., Jarjis, H., Holgate, A. M., Hanning, I., Scarpello, J. H. B., Johnson, I. T. \& Read, N. W. (1984). The mechanism of action of guar gum in improving glucose tolerance in man. Clinical Science 66, 329-336.

Blake, D. E., Roberts, F. G., Canibe, N., Bach Knudsen, K. E., Morgan, L. M. \& Ellis, P. R. (1993a). Quantitative determination of the effect of guar gum on gut hormone secretion in the pig and use of a transit time ultrasound flow probe. Proceedings of XV International Congress of Nutrition, Adelaide, Australia, p. 880. London: Smith-Gordon.

Blake, D. E., Roberts, F. R., Sissons, J. S., Canibe, N., Jones, C. L., Bach Knudsen, K. E. \& Ellis, P. R. (1993b). Quantitative assessment of the effect of non-starch polysaccharides on nutrient absorption in the pig: use of a transit time, ultrasound flow probe. Proceedings of the Nutrition Society 52, 200A.

Blanshard, J. M. V. \& Mitchell, J. R. (1988). Food Structure - its Creation and Evaluation. London: Butterworths.

Braaten, J. T., Wood, P. J., Scott, F. W., Reidel, K. D., Poste, L. M. \& Collins, M. W. (1992). Oat gum, a soluble fibre which lowers glucose and insulin in normal individuals after an oral glucose load: comparison with guar gum. American Journal of Clinical Nutrition 53, 1425-1430.

Brennan, C. S., Blake, D. E., Ellis, P. R. \& Schofield, J. D. (1996). Effect of guar galactomannan on wheat bread microstructure and on the in vitro and in vivo digestibility of starch in bread. Journal of Cereal Science 24, $151-160$.

British Nutrition Foundation (1990). Complex Carbohydrates in Foods. The Report of the British Nutrition Foundation's Task Force. London: Chapman and Hall.

Brown, N. J., Worlding, J., Rumsey, R. D. E. \& Read, N. W. (1988). The effect of guar gum on the distribution of a radiolabelled meal in the gastrointestinal tract of the rat. British Journal of Nutrition 88, 223-231.

Bueno, L., Praddaude, F., Fioramonti, J. \& Ruckesbusch, Y. (1981). Effect of dietary fibre on gastrointestinal motility and jejunal transit time in dogs. Gastroenterology 80, 701-707.

Carpita, N. C. (1990). The chemical structure of the cell walls of higher plants. In Dietary Fibre, Chemistry, Physiology and Health Effects, pp. 15-30 [D. Kritchevsky, C. Bonfield and J. W. Anderson, editors]. London: Plenum Press.

Cherbut, C., Albina, E., Champ, M., Doublier, J. L. \& Lecannu, G. (1990). Action of guar gum on the viscosity of digestive contents and on gastrointestinal motor function in pigs. Digestion 46, 205-213.

Crapo, P. A., Reaven. G. \& Olefsky, J. (1977). Postprandial plasma-glucose and -insulin responses to different complex carbohydrates. Diabetes 26, 1178-1183.

Dahlqvist, A. \& Borgström, B. (1961). Digestion and absorption of disaccharides in man. Biochemical Journal 81, 411-418.

de Gennes, P. G. (1979). Brownian motions of flexible polymer chains. Nature 282, 367-370.

Dickinson, E. (1992). An Introduction to Food Colloids. Oxford: Oxford University Press.

Dreher, M. L., Dreher, C. L. \& Berry, J. W. (1984). Starch digestibility of foods: a nutritional perspective. CRC Critical Reviews in Food Science and Nutrition 20, 47-71.

Eastwood, M. A. \& Morris, E. R. (1992). Physical properties of dietary fibre that influence physiological function: a model for polymers along the gastrointestinal tract. American Journal of Clinical Nutrition 55, $436-442$. 
Edwards, C. A., Johnson, I. T. \& Read, N. W. (1988). Do viscous polysaccharides slow absorption by inhibiting diffusion or convection? European Journal of Clinical Nutrition 42, 307-312.

Edwards, C. A. \& Read, N. W. (1990). Fibre and small intestinal function. In Dietary Fibre Perspectives 2, pp. 52-75 [A. R. Leeds and V. J. Burley, editors]. London: John Libbey.

Ellis, P. R., Dawoud, F. M. \& Morris, E. R. (1991). Blood glucose, plasma insulin and sensory responses to guarcontaining wheat breads: effect of molecular weight and particle size of guar gum. British Journal of Nutrition 66, 363-379.

Ellis, P. R. \& Morris, E. R. (1991). Importance of the rate of hydration of pharmaceutical preparations of guar gum: a new in vitro monitoring method. Diabetic Medicine 8, 378-381.

Ellis, P. R., Morris, E. R. \& Low, A. G. (1986). Guar gum: the importance of reporting data on its physicochemical properties. Diabetic Medicine 3, 490-491.

Ellis, P. R., Roberts, F. G., Low, A. G. \& Morgan, L. M. (1995). The effect of high-molecular-weight guar gum on net apparent glucose absorption and net apparent insulin and gastric inhibitory polypeptide production in the growing pig: relationship to rheological changes in jejunal digesta. British Journal of Nutrition 74, 539-556.

Fisher, H., Van Der Noot, G. W., McGrath, W. S. \& Griminger, P. (1966). Dietary pectin and plasma cholesterol in swine. Journal of Atherosclerosis Research 6, 190-191.

Fogel, M. R. \& Gray, G. M. (1973). Starch hydrolysis in man: an intraluminal process not requiring membrane digestion. Journal of Applied Physiology 35, 263-267.

Gatenby, S. J., Ellis, P. R., Morgan, L. M., Dawoud, F. M. \& Judd, P. A. (1996). Effect of depolymerised guar gum on acute metabolic variables in patients with non-insulin-dependent diabetes. Diabetic Medicine 13, 358-364.

Gee, J. M., Blackburn, N. A. \& Johnson, I. T. (1983). The influence of guar gum on intestinal cholesterol transport in the rat. British Journal of Nutrition 50, 215-224.

Grenfeldt, Y., Björk, I., Drews, A. \& Tovar, J. (1992). An in vitro procedure based on chewing to predict metabolic response to starch in cereal and legume products. European Journal of Clinical Nutrition 46, $649-660$.

Heppell, L. M. J. \& Rainbird, A. L. (1985). Effect of the physical form of dietary guar gum on nutrient absorption in the pig. In Proceedings of the Third International Seminar on Digestive Physiology and Nutrient Absorption in the Pig, pp. 58-60 [A. Just, H. Jorgensen and J. A. Fernandez, editors]. Copenhagen: National Institute of Animal Science.

Holman, R. R., Steemson, J., Darling, P. \& Turner, R. C. (1987). No glycaemic benefit from guar administration in NIDDM. Diabetes Care 10, 68-71.

Jenkins, D. J. A., Gassull, M. A., Leeds, A. R., Metz, G., Dilawari, J. B., Slavin, B. \& Blendis, L. M. (1977). Effect of dietary fibre on complications of gastric surgery: prevention of postprandial hyperglycaemia by pectin. Gastroenterology 72, 215-217.

Jenkins, D. J. A., Goff, D. V., Leeds, A. R., Alberti, R. G., Wolever, T. M. S., Gassull, M. A. \& Hockaday, T. D. R. (1976). Unabsorbable carbohydrates and diabetes: decreased post-prandial hyperglycaemia. Lancet 2, $170-174$.

Jenkins, D. J. A., Wolever, T. M. S., Jenkins, D. J. A., Thompson, L. U., Rao, A. V. \& Francis, T. (1986). The glycaemic index: blood glucose response to foods. In Dietary Fibre and Clinical Aspects, pp. 167-179 [G. V. Vahouny and D. Kritchevsky, editors]. New York: Plenum Press.

Jenkins, D. J. A., Wolever, T. M. S., Leeds, A. R., Gassull, M. A., Haisman, P., Dilawari, J., Goff, D. V., Metz, G. L. \& Alberti, K. G. M. M. (1978). Dietary fibre, fibre analogues and glucose tolerance: importance of viscosity. British Medical Journal i, 1353-1354.

Johansen, H. N., Bach Knudsen, K. E., Sandström, B. \& Skjøth, F. (1996). Effects of varying content of soluble dietary fibre from wheat flour and oat milling fractions on gastric emptying in pigs. British Journal of Nutrition 75, 339-351.

Johansen, H. N., Wood, P. J. \& Bach Knudsen, K. E. (1993). Molecular weight changes in the $(1 \rightarrow 3)(1 \rightarrow 4)-\beta$ D-glucan of oats incurred by the digestive processes in the upper gastrointestinal tract of pigs. Joumal of Agricultural and Food Chemistry 41, 2347-2352.

Leeds, A. R., Bolster, N. R., Andrews, R. \& Truswell, A. J. (1979). Meal viscosity, gastric emptying and glucose absorption in the rat. Proceedings of the Nutrition Society 38, 44A.

Lin, T. M., Kim, K. S., Karvinen, E. \& Ivy, A. C. (1957). Effect of dietary pectin, 'protopectin' and gum arabic on cholesterol secretion in rats. American Journal of Physiology 188, 66-70.

Low, A. G. (1990). Nutritional regulation of gastric secretion, digestion and emptying. Nutrition Research Reviews 3, 229-252. 
Macagno, E. O., Christensen, J. \& Lee, C. L. (1982). Modelling the effect of wall movement on absorption in the intestine. American Journal of Physiology 243, G541-G550.

Meyer, J. H. \& Doty, J. E. (1988). GI transit and absorption of solid food: multiple effects of guar. American Journal of Clinical Nutrition 48, 267-273.

Meyer, J. H., Gu, Y. G., Jehn, D. \& Taylor, I. L. (1988). Intragastric vs intraintestinal viscous polymers and glucose tolerance after liquid meals of glucose. American Joumal of Clinical Nutrition 48, $260-266$.

Morgan, L. M. (1992). Insulin secretion and the entero-insular axis. In Nutrient Regulation of Insulin Secretion, pp. 1-22 [P. R. Flatt, editor]. London: Portland Press.

Morgan, L. M., Tredger, J. A., Madden, A., Kwasowski, P. \& Marks, V. (1985). The effect of guar gum on carbohydrate, fat and protein stimulated gut hormone secretion: modification of postprandial gastric inhibitory polypeptide and gastrin responses. British Journal of Nutrition 53, 467-475.

Morris, E. R. (1990). Shear-thinning of 'random coil' polysaccharides: characterisation by two parameters from a simple linear plot. Carbohydrate Polymers 13, 85-96.

Morris, E. R. (1992). Physico-chemical properties of food polysaccharides. In Dietary Fibre - A Component of Food, Nutritional Function in Health and Disease, pp. 41-56 [T. F. Schweizer and C. A. Edwards, editors]. London: Springer-Verlag.

O'Connor, N., Tredger, J. \& Morgan, L. (1981). Viscosity differences between various guar gums. Diabetologia 20, 612-615.

Rainbird, A. L. (1986). Effect of guar gum on gastric emptying of test meals of varying energy content in growing pigs. British Journal of Nutrition 55, 99-109.

Rainbird, A. L. \& Low, A. G. (1986). Effect of guar gum on gastric emptying in growing pigs. British Journal of Nutrition 55, 87-98.

Rainbird, A. L. \& Sissons, J. W. (1985). Effect of gastric cannulation on gastrointestinal motility in the pig. In Third International Seminar On Digestive Physiology and Nutrition in the Pig, pp. 66-71 [A. Just, H. Jorgensen and J. A. Fernandez, editors]. Copenhagen: National Institute of Animal Science.

Rayment, P., Ross-Murphy, S. B. \& Ellis, P. R. (1995). Rheological properties of guar galactomannan and rice starch mixtures - 1. Steady shear measurements. Carbohydrate Polymers 28, 121-130.

Rayment, P., Ross-Murphy, S. B. \& Ellis, P. R. (1996). Rheology of guar galactomannan/rice starch mixtures. In Gums and Stabilisers for the Food Industry, vol. 8 [G. O. Philips, D. J. Wedlock and P. A. Williams, editors]. Oxford: Pergamon Press (In the Press).

Rees, D. A. (1977). Polysaccharide Shapes. London: Chapman and Hall.

Rérat, A., Vaissade, P. \& Vaugelade, P. (1988). Absorption kinetics of dietary hydrolysis products in conscious pigs given diets with different amounts of fish protein. 1. Amino-nitrogen and glucose. British Journal of Nutrition 60, 91-104.

Rérat, A., Vaugelade, P. \& Villiers, P. (1980). A new method for measuring the absorption of nutrients in the pig: critical examination. In Current Concepts of Digestion and Absorption in Pigs, pp. 177-214 [A. G. Low and I. G. Partridge, editors]. Reading: National Institute for Research into Dairying.

Roberts, F. G., Smith, H. A., Low, A. G. \& Ellis, P. R. (1990a). Influence of wheat breads containing guar flour supplements of high and low molecular weights on viscosity of jejunal digesta in the pig. In Dietary Fibre: Chemical and Biological Aspects, pp. 164-168 [D. A. T. Southgate, K. Waldren, I. T. Johnson and G. R. Fenwick, editors]. Cambridge: The Royal Society of Chemistry.

Roberts, F. G., Smith, H. A., Low, A. G., Ellis, P. R., Morris, E. R. \& Sambrook, I. E. (1990b). Influence of guar gum flour of different molecular weights on viscosity of jejunal digesta in the pig. Proceedings of the Nutrition Society 49, 53A.

Robinson, G., Ross-Murphy, S. B. \& Morris, E. R. (1982). Viscosity-molecular weight relationships, intrinsic chain flexibility and dynamic solution properties of guar galactomannan. Carbohydrate Research 107, 17-32.

Ross-Murphy, S. B. (1984). Rheological methods. In Biophysical Methods in Food Research, Critical Reports on Applied Chemistry, vol. 5, pp. 138-199 [H. W. S. Chan, editor]. Oxford: SCI Blackwell.

Ross-Murphy, S. B. (editor) (1994). Rheological methods. In Physical Techniques for the Study of Food Biopolymers, pp. 343-392. London: Blackie Academic and Professional.

Sambrook, I. E. \& Rainbird, A. L. (1985). The effect of guar gum and level and source of dietary fat on glucose tolerance in growing pigs. British Journal of Nutrition 54, 27-35.

Schwartz, S. E., Levine, R. A., Weinstock, R. S., Petokas, S., Mills, C. A. \& Thomas, F. D. (1988). Sustained pectin ingestion: effect on gastric emptying and glucose tolerance in non-insulin dependent diabetic patients. American Journal of Clinical Nutrition 48, 1413-1417. 
Selvendran, R. R., Stevens, B. J. H. \& Du Pont, M. S. (1987). Dietary fibre: chemistry, analysis and properties. In Advances in Food Research, vol. 31, pp. 118-213 [C. O. Chichester, E. M. Mrak and B. S. Schweigert, editors]. London: Academic Press.

Silvester, K. R., Englyst, H. N. \& Cummings, J. H. (1995). Ileal recovery of starch from whole diets containing resistant starch measured in vitro and fermentation of ileal effluent. American Journal of Clinical Nutrition 62, 403-411.

Simões Nunes, C. \& Malmlöf, K. (1992). Effects of guar gum and cellulose on glucose absorption, hormonal release and hepatic metabolism in the pig. British Journal of Nutrition 68, 693-700.

Stephen, A. M., Haddad, A. C. \& Phillips, S. F. (1983). Passage of carbohydrate into the colon. Direct measurements in humans. Gastroenterology 85, 589-595.

Tadesse, K. (1982). The efficacy of dietary fibre on gastric secretion and emptying in man. Proceedings of the Physiological Society 332, 102P.

Thibault, J. F., Lahaye, M. \& Guillon, F. (1992). Physico-chemical properties of food plant cell walls. In Dietary Fibre - A Component of Food. Nutritional Function in Health and Disease, pp. 21-39 [T. F. Schweizer and C. A. Edwards, editors] London: Springer-Verlag.

Tovar, J., de Francisco, A., Björck, I. \& Asp, N.-G. (1991). Relationship between microstructure and in vitro digestibility of starch in pre-cooked leguminous seed flours. Food Structure 10, 19-26.

Vincent, J. F. V. (1990). Texture of plants and fruits. In Feeding and the Texture of Foods, pp. 19-33 [J. F. V. Vincent and P. J. Lillford, editors]. Cambridge: Cambridge University Press.

Wilmhurst, P. \& Crawley, J. C. W. (1980). The measurement of gastric transit time in obese subjects using ${ }^{24} \mathrm{Na}$ and the effects of energy content and guar gum on gastric emptying and satiety. British Journal of Nutrition 44, 1-6.

Wood, P. J. (editor) (1993). Physicochemical characteristics and physiological properties of oat $(1 \rightarrow 3)(1 \rightarrow 4)-\beta-$ D-glucan. In Oat Bran, pp. 83-112. St Paul, Minn.: American Association of Cereal Chemists.

Wood, P. J., Braaten, J. T., Scott, F. W., Doreen, K., Reidel, K. D., Wolynetz, M. S. \& Collins, M. W. (1994). Effect of dose and modification of viscous properties of oat gum on plasma glucose and insulin following an oral glucose load. British Journal of Nutrition 72, 731-733.

Würsch, P., Del Vedovo, S. \& Koellreutter, B. (1986). Cell structure and starch nature as key determinants of the digestion rate of starch in legume. American Journal of Clinical Nutrition 43, 25-29.

Zebrowska, T. \& Low, A. G. (1987). The influence of diets based on whole wheat, wheat flour and wheat bran on exocrine pancreatic secretion in pigs. Journal of Nutrition 117, 1212-1216. 